\title{
Study of SVM-DTC Strategy on Drive Motor of Cable Winch
}

\author{
Lawu Zhou ${ }^{1,2}$, Xiong Deng ${ }^{1}$, Bonan $\mathrm{An}^{1}$ and Jun Gao ${ }^{1}$ \\ ${ }^{1}$ College of Electrical and Information Engineering, Hunan University, Changsha 410082, China \\ ${ }^{2}$ College of Electrical and Information Engineering, Changsha University of Science \& Technology, Changsha 410114, China)
}

\begin{abstract}
Cable winch is a crucial component of the shore power system, and Permanent Magnet Synchronous Motor (PMSM) with high efficiency and good maintainability is always used as the drive motor for ship cable winch. In order to deal with the various and complex ocean environment, it is rather important for cable winches to keep the tension constant when picking and laying cables so as to realize constant torque control. According to the particularity of cable winch load which includes time variant, sudden change, and non-linearity, the combination of self-adapting fuzzy PID controller and direct torque control (DTC) strategy modulated by space vector is presented in this thesis to realize the control. Meanwhile, Matlab/Simulink is used to verify this control strategy. The result indicates that a drive motor controlled by SVM-DTC control strategy based on self-adapting fuzzy PID control can not only maintain the advantages of direct torque control well, but also present excellent dynamic and static characteristics at the same time, which would effectively reduce electromagnetic torque and flux linkage ripple. Therefore it is quite adapTable for the cable winch drive system.
\end{abstract}

Keyword-cable winch; PMSM; tension control; fuzzy self-adjusting PI vector control; SVM-DTC

\section{INTRODUCTION}

With the popularity application of marine shore power technology, large marines to pock in the harbor by shore power supply to meet the demand of marines lighting. Between shore power system and electrical devices on marine should be connected through cable, and usually adopt constant speed permanent magnet synchronous motors(PMSM) as a cable winch drive motor, to achieve cable release two-way. At the same time, marine cable release is different from the motor driven load on the land, the important thing is that the tension change constantly in the process of the cable twisted and released, and presents the characteristic of non-linear, time-varying and saturated. In order to reduce the impact force of the cable, achieve cable release fast and steady, required the drive motor adjust to the load tracing property is stronger, short setting time, realize the cable constant tension control.

The literature [2-4] proposed many of control methods to PMSM which direct torque control realize direct control to torque and flux linkage, a more direct and effective vector control, but the disadvantage is that the control accuracy is not high and cause torque ripple is bigger. The literature [5] introduced double fuzzy control to improve the problem of large torque ripple in direct torque control method, the flux trajectory roundness is better, but its drawback is slow dynamic response. Combining with the actual proposed based on adaptive fuzzy PID control space vector pulse width of the direct torque control (SVM - DTC) strategy to drive the cable winch cable constant tension control, through the simulation and experiment, testing in the case of load changes, the control system can stability control drive motor, constant tension control.

\section{CABLE WINCH DRIVE SYSTEM}

Cable winch device is the key to the ship and shore power connection technology. Compared with the traditional cable drum, cable reel has a small installation space, row line, reliable, low cost, etc. Mainly by the driving mechanism, reduction gearbox, cable-ring boxes, cable reel and cable buffering mechanism parts.

Marine cable reel is small volume, simple maintenance and approximate constant torque output of hysteresis type cable reel, good synchronization performance, small cable tension of elastic cable reel, variable torque output torque motor type cable reel, heavy hammer type cable reel, etc.

\section{THE SVM - DTC PRINCIPLE OF ADAPTIVE FUZZY PID}

\section{A. Permanent Magnet Synchronous Motor Mathematical Mode}

Install permanent magnet excited on permanent magnet synchronous motor rotor, and the stationary the stator side also produce magnetic field through the current, both synthesis of rotating magnetic field. Non-salient pole rotor is mainly composed of alloy steel forgings whole, the cross-direct axis self-inductance equal. When the motor parameters are calculated, there will be $a, b$ and $c$ of the axes three-phase static coordinate system after Clarke transformation, into axes for $\alpha$ and $\beta$ of the axes two-phase static coordinate system to describe the motor parameters $^{[8]}$., As shown in Figure I.

Where, $\Psi_{\mathrm{s}}$ is the stator flux linkage, and $\Psi_{\mathrm{f}}$ is the rotor flux linkage; $\delta$ is the angle between $\Psi_{\mathrm{s}}$ and $\Psi_{\mathrm{f}}$, non-salient pole PMSM parameters are given by type (1) (4):

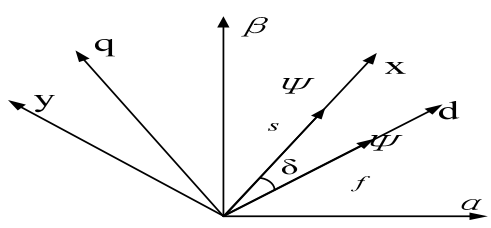

FIGURE I. VECTOR DIAGRAM OF MOTOR IN DIFFERENT COORDINATE SYSTEM 


$$
\begin{gathered}
{\left[\begin{array}{c}
u_{\mathrm{s} \alpha} \\
u_{\mathrm{s} \beta}
\end{array}\right]=\sqrt{\frac{2}{3}}\left[\begin{array}{rrr}
1 & -\frac{1}{2} & -\frac{1}{2} \\
0 & \frac{\sqrt{3}}{2} & -\frac{\sqrt{3}}{2}
\end{array}\right]\left[\begin{array}{l}
u_{\mathrm{a}} \\
u_{\mathrm{b}} \\
u_{\mathrm{c}}
\end{array}\right]} \\
{\left[\begin{array}{c}
i_{\mathrm{s} \alpha} \\
i_{\mathrm{s} \beta}
\end{array}\right]=\sqrt{\frac{2}{3}}\left[\begin{array}{ccc}
1 & -\frac{1}{2} & -\frac{1}{2} \\
0 & \frac{\sqrt{3}}{2} & -\frac{\sqrt{3}}{2}
\end{array}\right]\left[\begin{array}{l}
i_{a} \\
i_{b} \\
i_{c}
\end{array}\right]} \\
T_{\mathrm{em}}=\frac{3}{2} P\left(\psi_{\mathrm{s} \alpha} i_{\mathrm{s} \beta}-\psi_{\mathrm{s} \beta} i_{\mathrm{s} \alpha}\right) \\
\left\{\begin{array}{l}
\psi_{\mathrm{s} \alpha}=\int\left(u_{\mathrm{s} \alpha}-R_{\mathrm{s}} i_{\mathrm{s} \alpha}\right) \mathrm{d} t \\
\psi_{\mathrm{s} \beta}=\int\left(u_{\mathrm{s} \beta}-R_{\mathrm{s}} i_{\mathrm{s} \beta}\right) \mathrm{d} t \\
\psi=\sqrt{\psi_{\mathrm{s} \alpha}^{2}+\psi_{\mathrm{s} \beta}^{2}} \\
\theta=\arctan \frac{\psi_{\mathrm{s} \beta}}{\psi_{\mathrm{s} \alpha}}
\end{array}\right.
\end{gathered}
$$

where, $u_{\mathrm{s}}$ is the stator voltage; $i_{\mathrm{s}}$ is the stator current; $T_{\mathrm{em}}$ is the electromagnetic torque of drive motor; $P$ is the NO. of pole pair; $\Psi_{\mathrm{s}}$ is the stator flux linkage; $\Psi$ is the amplitude of $\Psi_{\mathrm{s}} ; \theta$ is the angle of stator flux linkage; $R_{\mathrm{S}}$ is the equivalent resistance of armature.

\section{B. Constant Tension Control Analysis}

When the winch cable runs, the motion equations of drive motor is given by type (5) and (6)

$$
\begin{aligned}
& T_{\mathrm{F}}=T_{\mathrm{em}}+T_{0}+J \frac{\mathrm{d} \omega}{\mathrm{d} t} \\
& T_{F}=T_{\mathrm{em}}+T_{0}+T_{\mathrm{D}}
\end{aligned}
$$

where, $T_{\mathrm{F}}$ is the load torque; $T_{0}$ is the no-load torque; $J$ is the moment of inertia; $\omega$ is the rotor angular velocity; $T_{\mathrm{D}}$ is the dynamic torque. Usually, cable tension is bigger, $T_{0}$ can be ignored, compared with it. In the process of motor running smoothly, drive load is given by type (7) and (8)

$$
\begin{gathered}
T_{\mathrm{F}}=F \frac{D}{2} \\
T_{\mathrm{F}}=T_{\mathrm{em}}
\end{gathered}
$$

where, $F=$ cable tension, and $D=$ cable reel diameter. As we know from that, when motor drives cable winch steady speed running, the cable line speed and tension is constant. But in practical engineering, the roll diameter and the moment of inertia reel transformation unceasingly, it will inevitably cause changes in cable tension. So to maintain constant cables tension, the electromagnetic torque of motor is required to be able to quickly and accurately track changes in tension cable, then the dynamic torque(TD) compensation in type (6) should be considered, such as (9) and (10)

$$
\begin{gathered}
T_{\mathrm{D}}=\left(J_{\mathrm{P}}+J_{\mathrm{M}}\right) \frac{\mathrm{d} \omega}{\mathrm{d} t} \\
J_{\mathrm{P}}=\int_{r}^{R}(2 \pi R \rho b) R^{2} \mathrm{~d} R=\frac{\pi}{2} \rho b\left(R^{4}-r^{4}\right)
\end{gathered}
$$

where, $J_{\mathrm{P}}$ is the moment of inertia of cable reel; $J_{\mathrm{M}}$ is the moment of inertia of cable cylinder storage; $R$ is the cable reel radius; $r$ is the cable cylinder storage radius; $\rho$ is the cable density; $b$ is the cable width. If $D=2 R, d=2 r$, then given by (11)

$$
J_{\mathrm{P}}=\frac{\pi}{32} \rho b\left(D^{4}-d^{4}\right)
$$

In calculation of type (9) (11), it is assumed type (12)

$$
T_{\mathrm{D}}=\frac{2}{D}\left[\frac{\pi}{32} \rho b\left(D^{4}-d^{4}\right)+J_{\mathrm{M}}\right] \frac{\mathrm{d} v}{\mathrm{~d} t}
$$

where, $v$ is the rotor line speed of drive motor, analysis, grasps the cable winch drum diameter $\mathrm{D}$ and speed rate $\mathrm{d} v / \mathrm{d} t$ and other dynamic variables, can be drawn dynamic torque compensation required in the process of cable release, by adjusting the drive motor electromagnetic torque to control constant tension in the process of cable. Therefore, cable tension control of the ship, is to control the drive motor torque.

\section{The Adaptive Fuzzy PID Controller}

PID controller is simple and more effective, and its parameters are often fixed, unable to adapt to changes in the system, however, if combined with fuzzy control which has the advantages of good adaptability and strong robustness ${ }^{[9]}$. So that can be composed adaptive fuzzy control, fast adjustment for changes in the load, keep the cable winch fast and sTable operation.

Figure II is a two-dimensional schematic diagram of an adaptive fuzzy controller. As difference between the reference speed and the actual speed $E=n^{*}-n$ as an error, as the difference and the difference rate change of $E_{\mathrm{c}}=E_{i}-E_{i-1}$ as two inputs, while using three output ports, as modified $\Delta K_{\mathrm{p}}, \Delta K_{\mathrm{i}}$, and $\Delta K_{\mathrm{d}}$ as outputs. Given the original parameters is $K_{\mathrm{p} 0}, K_{\mathrm{i} 0}$, and $K_{\mathrm{d} 0}$, controller output is $T^{*}$. By P, I and $\mathrm{D}$ values for the selected logical controller to adjust the parameters, so that the output satisfies a predetermined expectations.

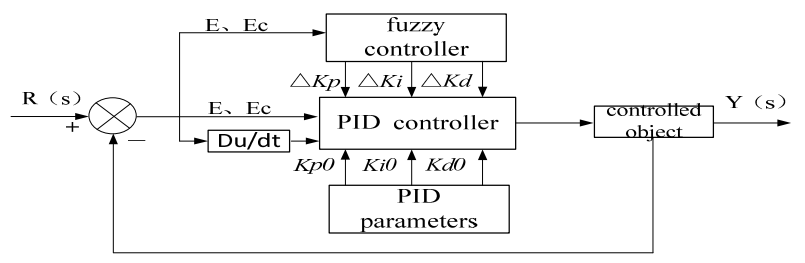

FIGURE II. FUZZY SELF-ADJUSTING PID FOR CABLE WINCH 
According to get the selected value for P, I and D and expertise to get $\mathrm{Kp}, \mathrm{Ki}$ and $\mathrm{Kd}$ fuzzy rules, such as Table I III:

TABLE I. $K_{\mathrm{P}}$ FUZZY CONTROL RULE TABLE

\begin{tabular}{cccccccc}
\hline \multirow{2}{*}{$E$} & \multicolumn{7}{c}{$E_{\mathrm{c}}$} \\
\cline { 2 - 7 } & NB & NM & NS & ZO & PS & PM & PB \\
\hline NB & PB & PB & PM & PM & PS & ZO & ZO \\
NM & PB & PB & PM & PS & PS & ZO & NS \\
NS & PM & PM & PM & PS & ZO & NS & NS \\
ZO & PM & PM & PS & ZO & NS & NM & NM \\
PS & PS & PS & ZO & NS & NS & NM & NM \\
PM & PS & ZO & NS & NM & NM & NM & NB \\
PB & ZO & ZO & NM & NM & NM & NB & NB \\
\hline
\end{tabular}

TABLE II. $K_{I}$ FUZZY CONTROL RULE TABLE

\begin{tabular}{|c|c|c|c|c|c|c|c|}
\hline \multirow{2}{*}{$E$} & \multicolumn{7}{|c|}{$E_{\mathrm{c}}$} \\
\hline & NB & NM & NS & $\mathrm{ZO}$ & PS & $\mathrm{PM}$ & PB \\
\hline NB & NB & NB & NM & NM & $\mathrm{NS}$ & $\mathrm{ZO}$ & $\mathrm{ZO}$ \\
\hline $\begin{array}{l}\mathrm{N} \\
\mathrm{M}\end{array}$ & NB & NB & $\mathrm{NM}$ & NS & NS & $\mathrm{ZO}$ & $\mathrm{ZO}$ \\
\hline NS & NB & NM & NS & NS & $\mathrm{ZO}$ & PS & PS \\
\hline $\mathrm{ZO}$ & NM & NM & NS & $\mathrm{ZO}$ & PS & PM & PM \\
\hline PS & NM & NS & $\mathrm{ZO}$ & PS & PS & NM & PB \\
\hline $\begin{array}{c}\mathrm{P} \\
\mathrm{M}\end{array}$ & $\mathrm{ZO}$ & $\mathrm{ZO}$ & PS & PS & PM & PB & PB \\
\hline PB & $\mathrm{ZO}$ & $\mathrm{ZO}$ & PS & PM & PM & PB & PB \\
\hline
\end{tabular}

TABLE III. $K_{D}$ FUZZY CONTROL RULE TABLE

\begin{tabular}{ccllllll}
\hline \multirow{2}{*}{$E$} & \multicolumn{7}{c}{$E_{\mathrm{c}}$} \\
\cline { 2 - 7 } & NB & NM & NS & ZO & PS & PM & PB \\
\hline NB & PS & NS & NB & NB & NB & NM & PS \\
NM & PS & NS & NB & NM & NM & NS & ZO \\
NS & ZO & NS & NM & NM & NS & NS & ZO \\
ZO & ZO & NS & NS & NS & NS & NS & ZO \\
PS & ZO & ZO & ZO & ZO & ZO & ZO & ZO \\
PM & PB & NS & PS & PS & PS & PS & PB \\
PB & PB & PM & PM & PM & PS & PS & PB \\
\hline
\end{tabular}

Regulators in real time to adjust to changing load and speed, to obtain the final correction parameters:

$$
\left\{\begin{array}{l}
K_{\mathrm{p}}=\Delta K_{\mathrm{P}}+K_{\mathrm{P} 1} \\
K_{\mathrm{i}}=\Delta K_{\mathrm{i}}+K_{\mathrm{i} 1} \\
K_{\mathrm{d}}=\Delta K_{\mathrm{d}}+K_{\mathrm{d} 1}
\end{array}\right.
$$

\section{SVM-DTC SYSTEM WITH ADAPTIVE FUZZY PID REALIZATION}

When using SVPWM to control, still maintaining constant amplitude of stator flux, control torque angle to control the electromagnetic torque ${ }^{[12]}$, which the key is calculated and the expected voltage vector $u_{\alpha}$ and $u_{\beta}{ }^{[13]}$. In the $\alpha$ and $\beta$ coordinate system is readily available:

$$
\left[\begin{array}{l}
u_{\mathrm{s} \alpha} \\
u_{\mathrm{s} \beta}
\end{array}\right]=\left[\begin{array}{cc}
R_{\mathrm{s}} & 0 \\
0 & R_{\mathrm{s}}
\end{array}\right]\left[\begin{array}{l}
i_{\mathrm{s} \alpha} \\
i_{\mathrm{s} \beta}
\end{array}\right]+p\left[\begin{array}{l}
\psi_{\mathrm{s} \alpha} \\
\psi_{\mathrm{s} \beta}
\end{array}\right]
$$

where, $\mathrm{p}$ is differential operator, and combined with the figure (2):

$$
\left\{\begin{array}{l}
u_{\alpha}=R_{\mathrm{s}} i_{\mathrm{s} \alpha}+\frac{\left|\psi_{\mathrm{ref}}\right| \cos (\theta+\Delta \theta)+|\psi| \cos (\theta)}{T_{\mathrm{s}}} \\
u_{\beta}=R_{\mathrm{s}} i_{\mathrm{s} \beta}+\frac{\left|\psi_{\mathrm{ref}}\right| \sin (\theta+\Delta \theta)-|\psi| \sin (\theta)}{T_{\mathrm{s}}}
\end{array}\right.
$$

where, $u_{\alpha}$ and $u_{\beta}$ is the component in the stator voltage $\alpha$ and $\beta$ axis; $\psi_{\text {ref }}$ is the stator flux reference; $\Delta \theta$ is load angle increment; $T_{\mathrm{s}}$ is sampling time. PMSM principle under the control of the SVM-DTC shown in figure III. Make $u_{\alpha}, u_{\beta}, u_{\mathrm{dc}}$ and $T_{s}$ are simultaneously input to the SVPWM module, output three-phase inverter control signal.

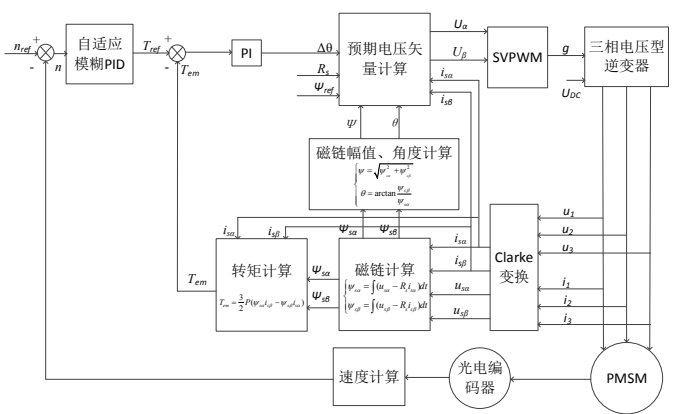

FIGURE III. PRINCIPLE DIAGRAM OF SVM-DTC FOR PMSM

\section{SiMULATION RESEARCH}

Cable winch drive system simulation using the specific parameters of the PMSM as follow: DC bus voltage $U_{\mathrm{dc}}=510 \mathrm{~V}$, stator resistance $R_{\mathrm{s}}=18.7 \Omega$, motor direct and quadrature axis inductance $L_{\mathrm{d}}=L_{\mathrm{q}}=0.00835 \mathrm{H}, \quad \mathrm{PWM}$ modulation period $T_{\mathrm{s}}=0.0001 \mathrm{~s}$, rotor flux $\psi_{\mathrm{f}}=0.175 \mathrm{~Wb}$, given reference stator flux $\psi_{\mathrm{ref}}=0.77 \mathrm{~Wb}$, number of pole pair $2 P=4$, motor moment of inertia $J=0.000025 \mathrm{~kg} \cdot \mathrm{m}^{2}$.

Cable winch drive system under different speed conditions, given a constant load $2 \mathrm{~N} \cdot \mathrm{m}$, compare with the static performance of the system, the results shown in Figure IV, the simulation results based on it was to be made as shown in Table IV.

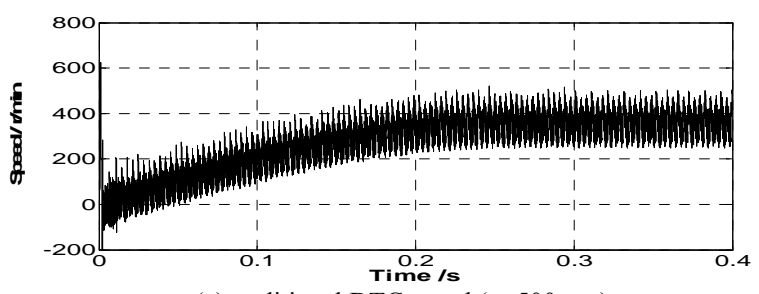

(a) traditional DTC speed $(\mathrm{n}=500 \mathrm{rpm})$

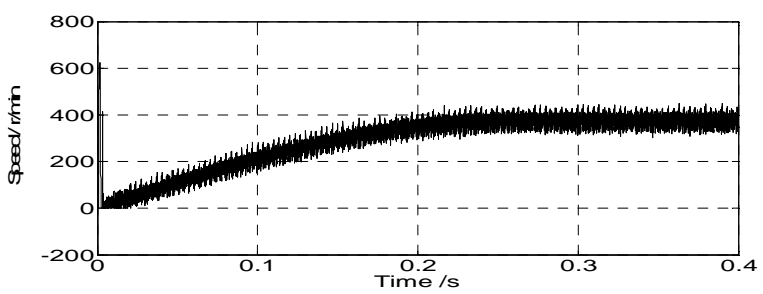

(b) SVM-DTC speed ( $\mathrm{n}=500 \mathrm{rpm})$ 


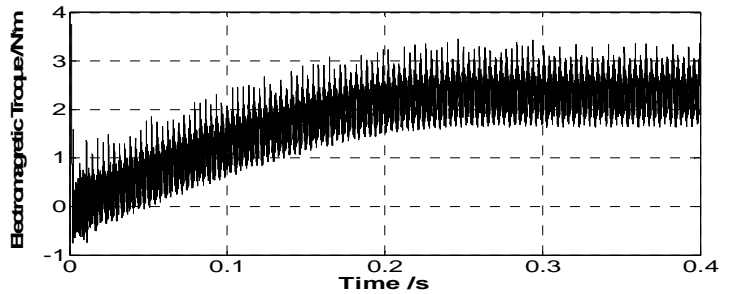

(c) traditional DTC torque $(\mathrm{n}=500 \mathrm{rpm})$

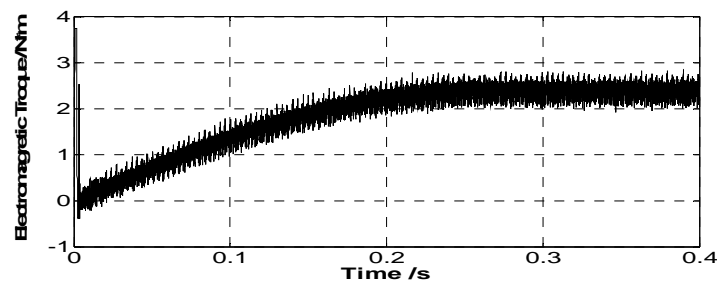

(d) SVM-DTC torque $(\mathrm{n}=500 \mathrm{rpm})$

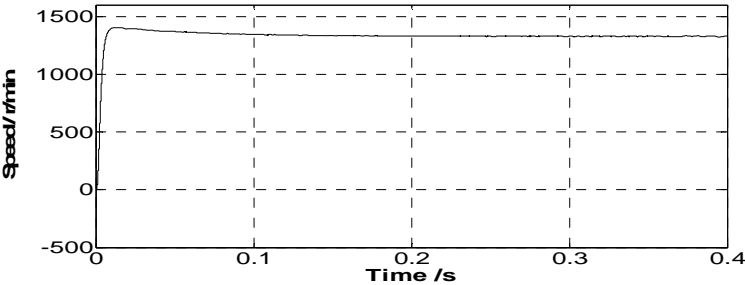

(e) traditional DTC speed $(\mathrm{n}=1500 \mathrm{rpm})$

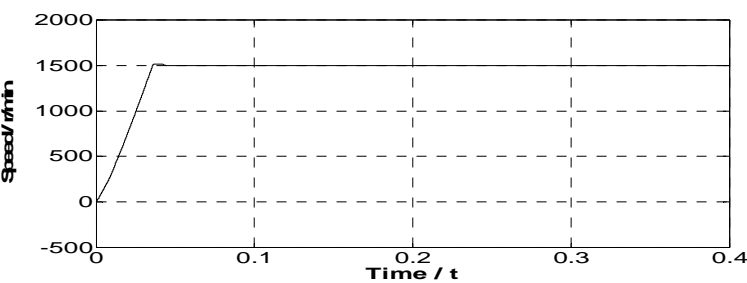

(f) SVM-DTC speed $(\mathrm{n}=1500 \mathrm{rpm})$

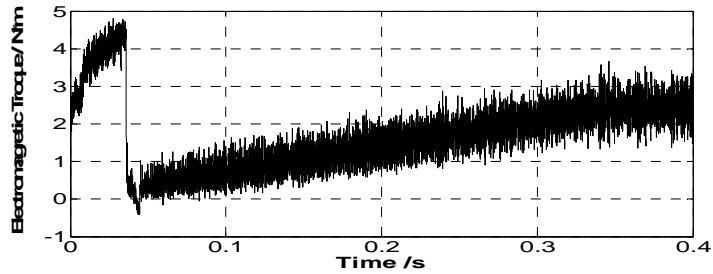

(g) traditional DTC torque $(\mathrm{n}=1500 \mathrm{rpm})$

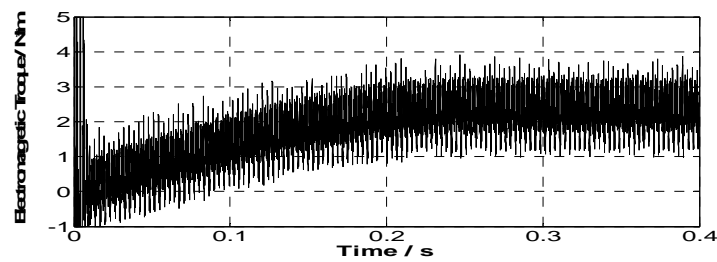

(h) SVM-DTC torque $(\mathrm{n}=1500 \mathrm{rpm})$

FIGURE IV. SPEED AND TORQUE WAVEFORMS UNDER DIFFERENT LOAD WITH DIFFERENT METHODS

TABLE IV. SPEED AND TORQUE RIPPLE UNDER DIFFERENT SPEEDS

\begin{tabular}{ccccc}
\hline \multirow{2}{*}{ speed $/(\mathrm{r} / \mathrm{min})$} & \multicolumn{2}{c}{ Traditional DTC } & \multicolumn{2}{c}{ SVM-DTC } \\
\cline { 2 - 5 } & $n /(\mathrm{r} / \mathrm{min})$ & $T_{\mathrm{e}} /(\mathrm{N} \cdot \mathrm{m})$ & $n /(\mathrm{r} / \mathrm{min})$ & $T_{\mathrm{e}} /(\mathrm{N} \cdot \mathrm{m})$ \\
\hline 500 & 4.4 & 0.46 & 3.7 & 0.37 \\
1500 & 26.9 & 0.69 & 18.8 & 0.49 \\
\hline
\end{tabular}

From Table IV can be concluded that compared to conventional DTC control strategy, SVM-DTC control strategy have higher accuracy in retracTable cable unit, better steady state performance.

\section{CONCLUSION}

Simulation results show that cable winch drive system have good speed stability and high precision, based SVM-DTC control strategy with adaptive fuzzy PID. Faced the various and complex ocean environment, this system can meet the demand of acceleration and deceleration during cable release. Drive motor electromagnetic torque under the control strategy can be quickly and efficiently track the load torque conversion, to achieve cable constant tension control. Meanwhile, improved the shortcomings of traditional direct torque control, used PWM modulation, Effectively reduced the electromagnetic torque ripple, higher accuracy, the output smoother, faster reaction. This Strategy is applicable to today's cable winch system, worthy studying further and applied to the production.

\section{REFERENCES}

[1] Xu Guohua, Zhang Junsheng, Xiang Xianbo. Underwater winch system driven by brush-less DC motor. The Ocean Engineering, 2006, 24(2): 123-129.

[2] Li Yaohua, Liu Weiguo. Comparison of the VC and DTC for the PMSM. Electric Drive, 2010, 40(10): 9-12, 17.

[3] Cheng Qiming, Cheng Yiman, Wang Yingfei. Overview of control strategies for AC motor. Power System Protection and Control, 2011, 39(9): 145-154.

[4] Tan Hengwei, Zheng Tianjiang. Study on the system of PMSM direct torque control based on SVPWM. The World of Inverters, 2010, (7): 60-64.

[5] Liu Yang, Wang Qinruo, Chen Sizhe. Research on PMSM double fuzzy adaptive direct torque control. Micoromotors, 2015, 48(2): 37-43.

[6] Liu Yingpei. Space vector modulated direct torque control for PMSM based on ADRC. Electric Power Automation Equipmen, 2011, 31(11): 78-82.

[7] Yang Jianfei, Hu Yuwen. Optimal direct torque control of permanent magnet synchronous motor. Proceedings of the CSEE, 2011, 31(27): 109-115.

[8] Gu Xin, Jiang Bo, Geng Qiang. Model predictive control for two permanent magnet synchronous motors with five-leg voltage source inverter. Advanced Technology of Electrical Engineering and Energy, 2015, 34(12): 25-30

[9] Wang Shuyan, Shi Yu, Feng Zhongxu. A Method for controlling a loading system based on a fuzzy PID controller. Mechanical Science and Technology for Aerospace Engineering, 2011, 30(1): 166-172.

[10] Feng Jinghuan, Xia Changliang, Wang Hechao. Improved deadbeat predictive current control strategy of permanent magnet synchronous motors. Advanced Technology of Electrical Engineering and Energy, 2015, 34(8): 1-6, 31 .

[11] A Khodadoost, A Radan. Novel comparative study between SVM, DTC and DTC-SVM in five-leg inverter to drive two motors independently. 4th Power Electronics, Drive Systems and Technologies Conference (PEDSTC) [C]. 2013. 294-300.

[12] Yang Junhua, Lv Huizi, Wu Jie, et al. Direct torque control strategy for brushless doubly-fed machines based on Popov hyperstability theory. Proceedings of the CSEE, 2009, 29(15): 107-113.

[13] Lin Qian, Ge Baoming, Bi Daqiang. Hardware-in-the-loop platform for permanent magnet synchronous machine control. Advanced Technology of Electrical Engineering and Energy, 2014, 33(3):76-80. 